\title{
Parvovirus infection and anaemia in a patient with
}

\section{AIDS: case report}

\author{
S A Mitchell, J M Welch, S Weston-Smith, F Nicholson, CS Bradbeer
}

\begin{abstract}
Opportunistic infections such as Pneumocystis carinii pneumonia are well-recognised in patients with the acquired immune deficiency syndrome (AIDS). Anaemia due to a variety of causes also occurs in AIDS. Persistent infection with parvovirus (B19) causing severe anaemia has been reported in patients with leukaemia and congenital immunodeficiency. A case is now reported of parvovirus infection and anaemia, in an adult with AIDS, which responded dramatically to immunoglobulin therapy.
\end{abstract}

\section{Case report}

A 26 year old heterosexual, black Ugandan, male presented in May 1988 with Pneumocystis carinii pneumonia, and was found to be HIV-antibody positive. Two months later he developed massive bilateral inguinal lymphadenopathy; Mycobacterium tuberculosis was isolated from an inguinal lymph node and he responded to treatment with rifampicin, isoniazid, pyrazinamide and ethambutol.

He then defaulted from follow-up until September 1988, when he presented with tiredness, and was found to be severely anaemic. Investigations showed a haemoglobin of $3.1 \mathrm{~g} / \mathrm{dl}$ (mean cell volume $79 \mathrm{fl}$ ) and absent reticulocytes, granulocytopenia of $0.6 \times 10^{9} / 1$, lymphopenia of $0.5 \times 10^{9} / 1$, but normal platelets $(297$ $\left.\times 10^{9} / 1\right)$. A direct anti-globulin test was negative.

Bone marrow examination revealed red cell aplasia; one granuloma cell was seen but no acid fast bacilli. Parvovirus DNA was detected in the serum (by dot blot) as were low concentrations of parvovirus-specific IgM and IgG (by radioimmune assay). Parvovirus particles were also detected in the serum by immune electron microscopy. During the next two months the patient remained reticulocytopenic, and required repeated blood transfusions.

Department of Genito-Urinary Medicine

S A Mitchell, J M Welch, C S Bradbeer

Department of Haematology

$S$ Weston-Smith

Department of Virology, St Thomas' Hospital Medical School, London

F Nicholson
His medication at this time was rifampicin, isoniazid, and co-trimoxazole. Parvovirus DNA and parvovirus-specific IgG persisted, but parvovirus-specific IgM disappeared. In December 1988 he was treated with intravenous immunoglobulin (Gamimune-N, Cutter) $300 \mathrm{mg} / \mathrm{kg} /$ day for 8 days over a two-week period. There were no side-effects. During treatment he devoloped a reticulocytosis (see fig) and his haemoglobin rose. After treatment a repeat bone marrow aspirate showed active erythropoiesis, and his haemoglobin remained stable at 11-12 g/l.

In February 1989 he started zidovudine, $250 \mathrm{mg}$ qds. Six weeks later his haemoglobin fell to $7 \cdot 0 \mathrm{~g} / \mathrm{dl}$ and he became reticulocytopenic. Zidovudine was stopped, but by May he was again transfusion dependent. Parvovirus DNA was not detected on three occasions during this four month period, but was demonstrated again in June, when a repeat bone marrow examination showed red cell aplasia, and granulomata but no acid fast bacilli. He was, therefore, treated with intravenous immunoglobulin as before, which again resulted in a reticulocytosis and a rise in haemoglobin (see graph).

\section{Discussion}

B19 parvovirus was discovered to be a human pathogen in $1975^{4}$ and in 1983 was found to be the cause of fifth disease (erythema infectiosum). ${ }^{5}$ More recently it has been detected as causing severe chronic anaemia in immunosuppressed patients. ${ }^{1-3}$

Experimental infection of healthy volunteers with B19 by intranasal inoculation ${ }^{6}$ produced temporary reticulocytopenia and fall in haemoglobin. In immuno-compromised patients, parvovirus infection may become chronic with erythroid hypoplasia, reticulocytopenia, and prolonged anaemia. ${ }^{7}$

In experimental infection an antibody response to B19 of both the IgM and IgG classes occurred in all volunteers who developed systemic infection; parvovirus-specific DNA was also detected in these volunteers. ${ }^{6}$ Since antibody responses are unreliable in immunocompromised patients, it is essential that tests to detect parvovirus or virus-specific DNA can be used. In our patient neither IgM nor IgG was present when parvovirus-specific DNA was demonstrated on the second occasion.

In healthy individuals infection with B19 may be 


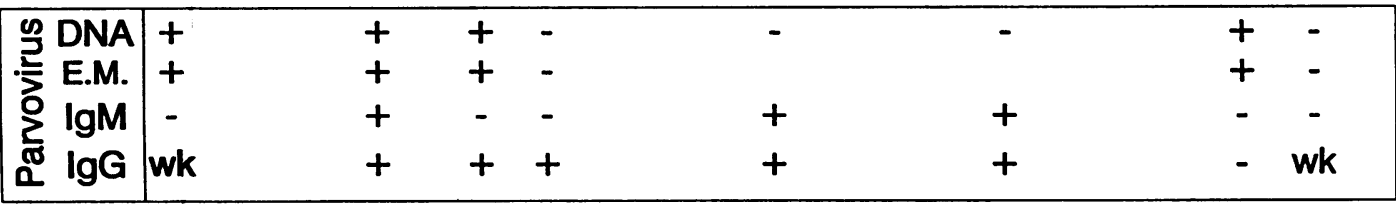

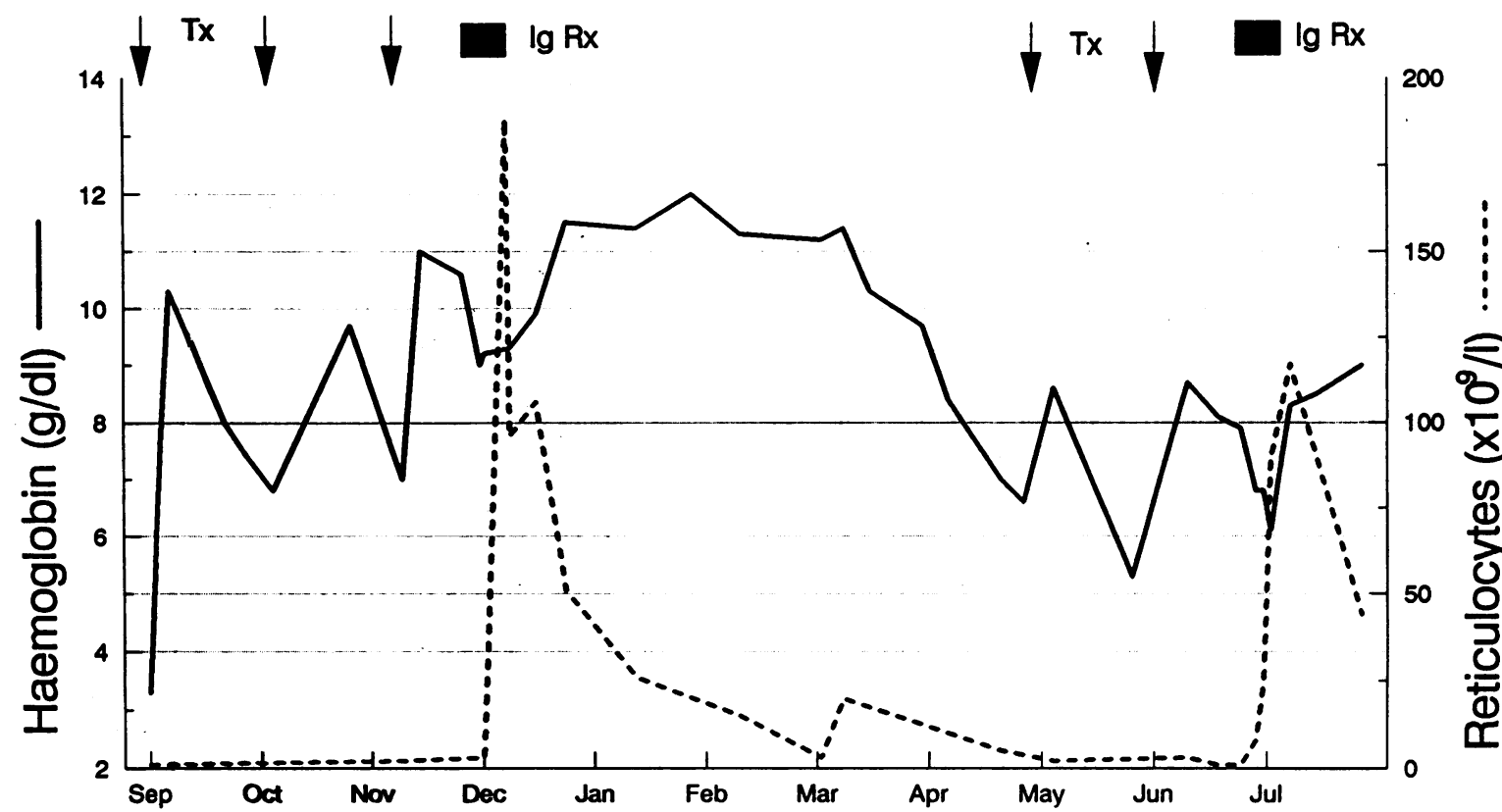

Fig Haematological and virological response to immunoglobulin.

asymptomatic or result in a mild, self-limiting disease characterised by fever, myalgia, arthralgia and rash. In some immunocompromised patients symptoms only develop once antibodies are produced ${ }^{\prime}$ or following infusion of Ig. Our patient had none of these symptoms before or after treatment with immunoglobulin.

Treatment in immune competent individuals is unnecessary. Kurtaman et $a^{\prime}$ described the disappearance of parvovirus-specific DNA from the serum and a reticulocytosis following infusion of immunoglobulin. Our patient responded to intravenous immunoglobulin with a dramatic reticulocytosis and subsequent rise in haemoglobin.

$\mathrm{Re}$-emergence of B19 infection and its consequent anaemia was re-treated successfully with immunoglobulin, giving a second reticulocytosis and increase in haemoglobin.

Although B19 infection is not a common cause of anaemia in patients with AIDS, this case highlights the importance of considering the infection in such patients, as haematological abnormalities may be reversed, in the short term, by treatment with immunoglobulin. We are now assessing low-dose intravenous immunoglobulin prophylaxis in this patient as an altermative to repeated blood transfusions.
We thank the Department of Virology, University College Hospital, London for carrying out tests for parvovirus-specific DNA and Dr Ian Chrystie, is Department of Virology, St. Thomas' Hospital for the immune electron microscopy.

Correspondence to: Dr S A Mitchell, Department of Genito-Urinary Medicine, St Thomas' Hospital, London SE1 7EH, UK

1 Kurtzman GJ, Cohen B, Mayers P, et al. Persistent B19 parvovirus infection as a cause of severe chronic anaema in children with acute lymphocytic leukaemia. Lancet 1988; ii: $1159-62$.

2 Coulombel L, Morinet F, Mielot F, Tchernia G. Parvovirus infection, Leukaemia and immunodeficiency. Lancet 1989; i:101-2.

3 Davidson JE, Gibson B, Gibson A, Evans TJ. Parvovirus infection, Leukaemia and immunodeficiency. Lancet 1989 i:102.

4 Cossart YE, Field AM, Cant B, et al. Parvovirus-like particles in human sera. Lancet 1975;1:72-3.

5 Cherry JD. Erythema infectiosum. In: Feigin RD, Cherry JD, eds. Textbook of Paediatric Infectious Disease. Philadelphia: Saunders, 1981:1401.

6 Anderson MJ, Higgins PG, Davis LR, et al. Experimental parvoviral infection in humans. J Infect Dis 1985;152:257-65.

7 Kurtzman J, Ozawa K, Cohen B, et al. Bone marrow failure due to chronic B19 parvovirus infection. N Engl J Med 1987;317: 287-94. 